\title{
Character Design in Games Analysis of Character Design Theory
}

\author{
Hagung Kuntjara S.W. \\ Visual Communication Design \\ School of Design, \\ Bina Nusantara University \\ Jakarta, Indonesia \\ hwijasa@binus.edu
}

\author{
Betha Almanfaluthi \\ Visual Communication Design \\ School of Design, \\ Bina Nusantara University \\ Jakarta, Indonesia \\ betha@binus.ac.id
}

\begin{abstract}
A character plays an important role in game sales on an application store. The first thing people notice when choosing a certain genre of a game on the application store is the character. Character appears in a game visual icon, alongside the name of the game and some stars representing the rating and the number of download. By looking at the game character, people will be able to tell the game genre and type, also the targeted users. Advanced technology might allow a game to develop better but analyzing the game character from its art and design aspect is also needed for it to be successful in the market. This paper will explain character design development and its art and design aspect using constructive method. The analysis can be used for better understanding on how games designers work and come up with the right idea of a game's characters based on the game's general idea.
\end{abstract}

Keywords—games; character; art and design.

\section{INTRODUCTION}

Everyone has their own favorite character that they might know either from a movie, commercial, a game they play, a comic book, or a packaging, even a mascot of a product they use. Character might show up as a stuffed animal or doll people hug and play with, on a printed t-shirt, a school bag, a pair of shoes, and as other things people use every day, but do they know how a character is developed and end up taking a part on their lives?

Character is the main thing in a presented story; a soul that brings a story to life. In a movie, a character will take the viewers along with its adventures, to follow it until the movie ends. In a game, a character is often in the form of an avatar whose look and attributes can be modified, based on the player preferences. The character will then go on an adventure, which goes on levels that have different complications and difficulties. The character is like the player themselves.
A character can be designed by one or a group of character designers, based on the story idea or the storyline. A character designer is a traditional artist who creates original drawing of characters for the visual media [1]. Character designers are professionals who constantly challenge themselves to explore their imagination to find the perfect and unique characters that differ from the existing ones. Character designers usually work with a wall full of pictures, a stack of sketches, and references from books, music and movies, photographs and research data. The whole process of designing a character is almost like creating magic, as it is a long process of putting a soul in a character and making it alive. Bancroft [1] states that the character designer's goal is to create characters that fulfill the needs of the script, scene, game, or story and suit for the storyline. There are no exact written steps to design the perfect character; designers can only rely on their improvisation and experiences, mixed with their usual ways of designing.

People will find various choices of games listed on the screen when they click open their application store. The most noticeable image that can attract people to read the game description is the game character. Once they click on the character icon, all the game features will be shown, from description, version, the game detailed information, the game developer, some preview images of the game levels, to customer ratings and reviews. Both characters and the visual look of a game create a visual experience journey that lets people have a taste of an adventure and challenges in a virtual world. Once people experience the journey, they might be interested in installing the game.

A character in a game plays a unique part. It is a representation of the player as it is the one going on a virtual world full of adventures and challenges [7]. Players can find different adventures and challenges in each level of the game. Games characters that might vary from humans, animals, aliens to zombies, and from fast cars, trucks, robots, and bubbles to balls, are controlled by the players. Some games characters' looks, attributes, and even personalities can also be controlled and customized. Design character and other games' assets are included in games art. 
Challenges and journeys experienced in a game help the game itself to make people interested in playing [10]. The challenges depend on how smart the artificial intelligence (AI) are [8]. Developing AI is a part of the process on creating a game. The process is called game design. it is a process of creating the content and rules of a game. A decent game design contains steps like creating objectives for players to achieve and setting up the rules of the game. As the players are challenged to make important decisions in pursuing these objectives [2].

Based on that, all aspects of a game, characters, icons, journey experience and challenges, are united in one whole design. Characters design and challenges, for example, are two inseparable things as the design of one aspect will affect the other [8].

There is no exact step on designing a character. Each games art designer has their own way to work but as they work in a team consisting of experts in different disciplines. Each expert working on the team must be able to understand each other's job and to contribute to the game's development process.

Famous illustrator Jon Burgerman [3] explains 20 top character design tips. He explains that creating good character design can be very complicated and there are a lot of things needed to be tackled when it comes to character design. Popular characters in cartoons, movies and commercials are often simple-looking. However, simple-looking characters are the ones that take time and efforts to be designed. Designers always try to keep the simplicity of a character simple so the targeted market remembers it for a long time.

Besides designing simple shapes and figures of a character for it to be easily recognized and liked, designers must add other interesting elements to shape a distinctive personality to the characters and eliminate personalities unneeded so the design will result in a strong and unique character.

20 tips from Burgerman [3] in character design:

1. Decide who it's aimed at

2. Decide where it will appear

3. Research other designs

4. Make your character distinctive

5. Use line qualities and style to describe your character

6. Use exaggerated characteristics

7. Choose colors carefully

8. Add accessories

9. $2 \mathrm{D}$ or $3 \mathrm{D}$ ?

10. Give your character personality

11. Focus on facial expression

12. Give your character goals and dreams

13. Build up a back story

14. Experiment!
15. Make your character design flexible

16. Swap mouse for pen

17. Get feedback from others

18. Hone, plan and polish your design

19. Create the right environment for your character

20. Fine-tune your figure

Those 20 tips focus on the goal of character design. for example, what for a character is made. Designers usually have their own brief, which is a line for their experiment zone; they will need to let their imagination flow when designing a character, trying out its shapes in sketches, and to decide on which media the character will appear and to figure out if the media demands details or simplicity in a character.

Designers are also required to keep looking for references and comparisons to avoid designing a similar character to the existing ones. They need to design something else that is unique and different.

Some other things that might help to make a character stand out are lines thickness, non-proportional shapes, color combinations, and addition of unique attributes like a uniqueshaped hat that can also help the character fly, or big-sized hand with a planet-lifting ability.

Characters must have personality. Game designers tend to write down all the characteristics of a character and the games art designers will be the one bringing it all to life. Personality is important as it is one of the ways a character interacts with other characters. It can also create a connection between a character and its targeted customers [8].

A character's facial expressions also need to be considered as important because they are the first thing people notice and able to tell the character's emotions and personality. It will be easy to tell if a character is a protagonist or an antagonist just based on its facial expressions, along with its physical posture and movements. Facial expression studies are the most important part of character studies. Designers usually practice their own facial expressions in the mirror to pay attention to the facial compositions detail; eyebrows, eyes, mouth and head movements, that help with deciding a character's emotions. Facial shapes also determine a character's personality.

A character will mean nothing if it is not designed with a goal. The whole storyline, conflict, challenges and ambience in a game will be complete if the main characters have a goal that the players must reach on each level. The elements will help with the game's appeal in the players' eyes.

\section{RESEARCH METHOD}

The research method used in this paper is a qualitative research through visual constructive. The constructive method is used in analyzing games character design theory, this method is used in giving examples of character design analysis by using the said theory, thus the understanding of how and why a character is designed. 


\section{Figure 1. Sago Mini, by Sago Sago Toys Inc.}

Constructive method takes the principles of an art movement that is driven by political interests to play a more social role. The idea of 'art for art' has been criticized; pure art, which has no purpose in society should be directed to serve the purposes of social meanings [5].

Constructive method principles adapted in this research is the aspect of sharpness, clarity, accuracy and efficiency. The ideas of constructivism affected the educational ethos of Bauhaus (progressive school of art and design) and this movement since the 1920 in Soviet, is used to design a special purpose [5]. Constructive method in this paper highlights how a game characters are created, are they accurate and sharp that suit the purpose and theory in the design.

The analysis can be used for better understanding on how games designers work and come up with the right idea of a game's characters based on the game's general idea. Some characters will be analyzed from their design aspect, using the constructivism method.

This constructivism analysis tries to analyze the artistic aspect of existing game characters from the design point of view. There will be three game characters that will be analyzed. These three game characters are form three different games. Each game has different audience target based on the players age range. They all will be deconstruct to analyze how the characters are formed, the role of the environments, also the gameplay about the rule of the games and challenges. From this deconstruction analysis, it will define how far the knowledge of design is applied on the game character.

\section{RESULT AND DISCUSSION}

The topic of games character designs and assets are covered in games art area. In a formal education, games art introduces understanding of creative aspects in a games industry. Having knowledge and doing projects are important in games art studies as it will help gain one's experience in their creative process, from storyboarding to designing games characters and environments.

Games art focuses mainly on the visual aspect of a game. However, a games art designer will also take part in the whole process of game designing; starting from looking for ideas to the launching of the game. Games art designers mostly work together with a games programmer team, as they must find the game's ideal goal.

\section{A. Deconstruction Analysis on Existing Game Characters}

1. Sago Mini Babies Dress Up

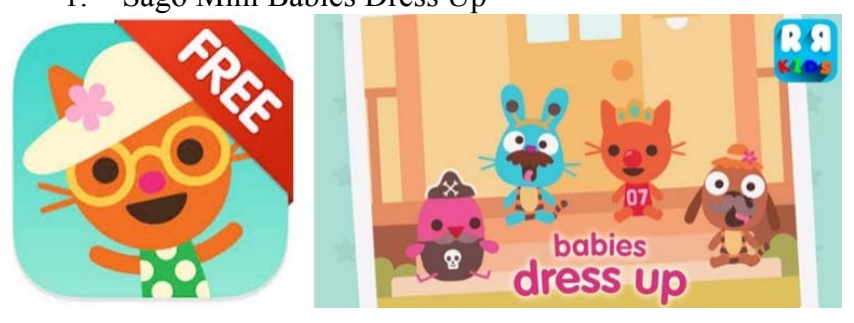

Sago Mini is an education game for toddlers. Launched on 2014 by Sago Sago Inc. Sago Mini games are sold as series, with the first serie that can be downloaded for free as an introduction game called Babies Dress Up. The other series of the Sago Mini games are paid games, including Sago Mini Superhero, Pet Café, Boats, Road Trip, Monsters, Ocean Swimmer, Music Box, Truck \& Diggers, and Robot Party. They are all available on Applstore, compatible with iPhone, iPad, and iPod touch.

\section{- Gameplay:}

Sago Mini Babies Dress Up is a great way for young child to not only have some awesome fun, but learn a few lessons about taking care of something. The idea of the game is that they'll be able to choose from a cast of Sago Mini characters that are babies, and their job is to care of them and make sure they're happy. How to play this game is that users are asked to put on clothes, hats, and accessories provided in the closet and wall on four cute characters. After the characters are dressed, they are gathered on the terrace to be taken their picture. Once the user touched the camera icon the application will capture and can be downloaded instantly as a picture collection. Kids can make creation as many as they want by mix and matching up the clothes, hats, and accessories. The game is easy to control and understand, and is filled with colorful graphics, endearing characters, and plenty of fun little elements to discover as kids go.

\section{- Games Art Character Design:}

There are 4 characters in Sago Mini - Babies Dress Up. They are Robin a baby bird, Jack a little rabbit, Jinja a sweet kitty, and Harvey a nice little dog. Robin with the soft pink color, Jack in cobalt blue color, Jinja an Orange color and Harvey have a brown color.

These four character designs use basic geometric circles for the head; the bodies use ovals; the hands, feet and ears have rounded corners, except Robin's feet which use lines. Each character face expression is created to be cute and adorable, with circle eyes, oval or rounded corner nose, except Robin which has a triangle beak.

There are four basic shapes in design; circle, triangle, square, and rectangle. These four basic shapes often used directly or combined with each other to get the desired shape. Basic shapes are easily recognized and memorable for kids. Circles evoke appealing, good characters, and typically used to connote cute, cuddy, friendly types. Drawings of babbies usually rely heavily on circular shapes as their visual cues.

Color scheme on each character uses pastel pink, light blue, orange and brown, these are recognizable and easily pronounced secondary and tertiary colors. The environment was made up of two scenes, on the terrace and in the dressing room. Assets that they have are clothes and accessories in different kind of themes; formal, casual, party, playing, 
superheroes, sports, vacations, etc. Every clothes and accessories are rounded corner shaped and pastel colored.

When users see the characters and the game atmosphere, they directly see the nuance of kids, playful, soft, inviting, and creativity to be responded. This game has high recommendation and designed suitably for kid's education.

\section{Subway Surfers}
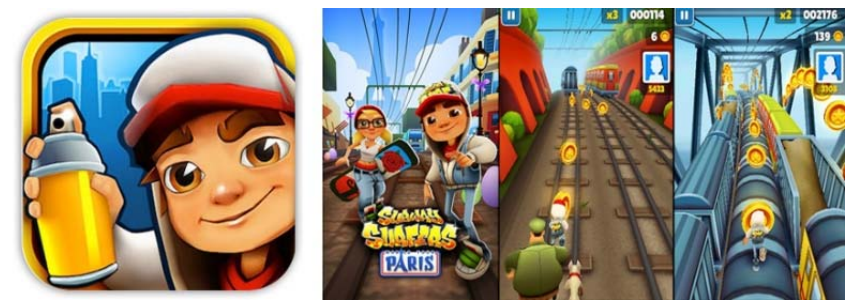

Figure 2. Subway Surfers, World Tour Paris, by Kiloo Games and Sybo Games.

Subway Surfers is a violence fantasy game for teenagers. The violence refers to the mischief of an underground teen riding his skateboard and graffiti. The theme of the game is that this teen tries to run away from the police because he was caught doing graffiti on the sub carriage. This game is an answer for the aspiration of young men that are searching for their identity. The game is targeted for kids above 9 years old.

Subway Surfers was launched in July 2015 by Kiloo Games and Sybo Games. It instantly became a hit. Since the first version released (version 1.42.0) with Sydney track subway as the theme, Kiloo has released Subway Surfers World Tour to various city all around the world. Subway Surfers has explored Sydney, Greece, New York, Kenya, Tokyo, North Pole, Hawaii, San Francisco, Middle East, Prague, Madagascar, Peru, Las Vegas, Singapore, Venice, Rio Brazil, Iceland, with their local youngster as the character.

Graphically this game emphasizes the cool factor with displaying vibrant colors, vivid HD graphics, even for the Apple version the game uses universal HD optimized graphic for retina resolution. Kiloo Games and Sybo Games keep improving the graphic interface, critical performance, Bug fixes and optimizations in order to please the fans. This game can be downloaded for free, but it provides coins, keys, and other accessories that users can buy. Subway Surfers games are available on Applestore and Googleplay Store.

\section{- Gameplay:}

Dash as fast as you can! Dodge the oncoming trains! Help Jake, Tricky \& Fresh escape from the grumpy officer and dog. Players can choose one favorite character, he would steal the opportunity to create graffiti on subway carriage, and when a fat officer and his dog caught him making that graffiti be prepared to push the run button. Along the way the train crosses the city, the hall trains, stations, tracks both singles and doubles.
Players must jump over a series of carriages running on the track and collect coins that float along the adventure. There will be trap bars that should be skipped or run through the bottom, there will always be a series of parked carriages to be avoided and a carriage from the other way unexpectedly. If the player hit the crossbar, parked carriage or wagon then he'll get caught by the officer and his dog. If he got caught by the officer he will be carried all the way back to the start.

If the player is lucky enough, this game gives engines as a tool to escape faster. It is given in a box icon. If players achieve that box icon, they will get the opportunity to have a superfast surfing hoverboard engine, paint powered jetpack, and lightning fast swipe acrobatics that makes the player float in the air and take up all the coins in a period of time.

This game is connected to the social medias so players can record and post scores and levels, also compare with other players around the world on how many coins gained.

\section{- Games Art Character Design:}

Character design of Subway Surfers consists of grungy young people from various countries with local names as the main characters. Both girls and boys with casual clothes and attribution can be choose as the character play with.

Ambient that is presented is the scenery around the railway from various cities around the world which have different uniqueness represented by their landmarks. The station atmosphere, subway hall, city, mountain, ice lake, desert, are some of the adventure with a standard HD Vivid Graphic resolution that is very pleasing for the eyes.

The depiction of a design character can be categorized as a cartoon with 3D techniques. Character designs in a hierarchical way can be grouped into several categories, it refers to several different levels of simplification on portraying the characters. Starting from the character with iconic form (Hello Kitty), simple (Cartoon TV), broad (expressive Roger Rabbit), comedy relief (humor through acting and dialogue), lead character (Sleeping Beauty, Cinderella), realistic (Hulk and most comic character).

All of the Subway Surfers characters have the 'lead character style' approach. The proportion of body and head of the characters are close to the normal human body proportions / realistic proportion with expressive faces. The character form is similar to the depiction of young style dolls from Bratz, American fashion dolls and merchandises manufactured by MGA Entertainment. Skin color, hairstyle, dress will be immediately recognizable where the character is coming from. All teenagers, have provoked personality, rebellious controversy, breaking rules, like new things, music, art, performance, dance, etc.

The colors that are used are very striking, sometimes tend to be vibrant and vivid, typical of the young people. The 3D animation approach allows the characters perform strongly. 


\section{Crisis Action}
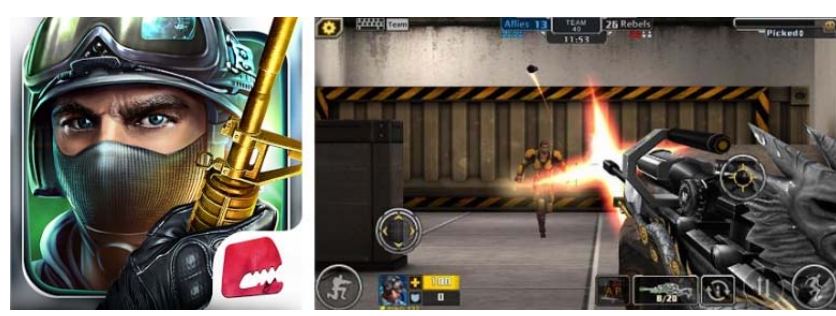

Figure 3. Crisis Action by Hero Games

\section{- Description:}

Crisis Action is the first eSports First person shooting mobile game, delicate 3D graphic, massive online multiplayer fighting in real-time. Online \& offline tournaments are being held, the players just download to join the PVE version and fight for real money! With more than 5,000,000 shooters, Crisis Action becomes the most popular real-time FPS mobile game in the world. Dozens of Battle Mode, the Same Immersive Shooting Pleasure.

There are a large number of pre-installed maps in the game, and strive to give more pleasure to game player. There are 10,000 Dollars, thousands of diamonds, exclusive Dragon guns for tournament winners. All Clans that join the tournament will get rewards. Join the clan \& kill the enemy whenever and wherever possible! First class clan needs strategy, more need player's courage and passion. If we were brothers, we would fight together!

Crisis Action first released on November 2015 in version 1.0 .1 , it has already undergone several improvements including optimized user interface, game security upgrade, bug fixed, revival coin \& music packs, new map, legendary weapon and support Thai \& Indonesian market up to version 1.2.2 in 2016. Crisis Action is produced by Hero Games. The game is for people above 17 years old, because it contains adult materials, including infrequent/mild cartoon or violence fantasy, frequent/Intense realistic violence, frequent/intense mature/suggestive themes.

This game can be downloaded for free, but it provides diamonds and other accessories that players can buy. This game application is available on Applestore and Googleplay store.

\section{- Gameplay:}

Crisis Action can be played on a single mode, multiplayer mode, solo mode, Biochemical mode and Up to 5V5 multiplayer battle mode. For the single mode, there will be stages to help player to improve shooting skills. For the multiplayer mode, The more the enemy, the more dangerous. When you play on a solo mode, this is a stage for personal player to enjoy the games. If players play on the team mode there will be friends and enemies, friends should fight together, join the clan and kill the enemies. In Crisis Action, there is also a mode call Biochemical mode, who will be the next infection? Let's wait for the dawn! Last, this game has a battle mode on it's Up to 5V5 multiplayers battle mode, more free and more fair to fight!

\section{- Games Art Character Design:}

The games art in Action Crisis presented in a hyper-realist form. Characters and ambient are designed as realistic as possible, it is expected that the player feels like plunging into the game experiencing fierce battle. In the category of character design, it is a realistic character approach, as clear as watching blue-ray HD video.

Besides the main character of the individual players, other characters that appear are the team of the clan and they are usually uniformed, then there are also the enemy characters with different colors. Almost hard to recognize which are the enemies and which are teammates, it is no wonder the novice player will often shoot their own teammates. This situation also makes the tensions escalate, the enemies can come from any direction. Players ran after or escape from the enemies while shooting. There are a variety of weapons ranging from knives, pistols, sniper rifles, magazine gun and bombs. Attributes that are used are special forces uniform with vast, hats, gloves, and boots, including the special glasses. Character visualization emphasis is created as realistic as possible in order to pursue an atmosphere like plunging in the actual battle area.

The tournament ambient is designed in different situations, in the building, in the warehouse, in the underground parking area, up to the roof of a building. 3D animations allow visualization of the games look realistic and sometimes even exceed reality. Assisted by map navigation buttons, it makes various virtual points of view that increased sophisticated impression. This is the real battle situation if the technology, fighting spirit, and strategy intelligence combined. Thrilling sensations experience will make players reluctant to finish this game and continue to follow the tournament collect points, weapons, tricks and map navigation.

\section{CONCLUSION}

Character design in games, well-known as games art material, requires knowledge and constant practice. Designers gain their knowledge from design studies, covering all elements like shapes and colors, composition, drawing, etc. Those elements will then be turned from ideas to real characters. Designing characters, games storyline, challenges, mission, and surroundings are inseparable things in video games. A character's personality must be designed based on the game's storyline and challenges. Ideas from game designers will be turned into a gameplay and go through a gamification process. Along with game programmers, 
games art designers will then complete the game's assets and look for the game's most ideal goal. Before finishing the game and finally launching it, the game developer will constantly try the game out so they can perfect it.

\section{REFERENCES}

[1] [1] Bancroft, T. (2006). Creating Character with Personality. New York: Crown Publishing Group.

[2] Brathwaite, B., Schreiber, I. (2008). Challenges for Game Designers. Boston: Cengage Learning.

[3] Burgerman, J. (2015). 20 top character design tips. http://www. creativebloq.com/character-design/tips-5132643 (accessed on September 7, 2016).

[4] Hero Games. (2014). Crisis Action-eSports FPS (Version 1.9.2). https://play.google.com/store/apps/details?id=com.herogames.gpla y.crisisactionsa\&hl $=$ en

[5] Kardinata, H. (2015). Desain Grafis Indonesia dalam Pusaran Desain Grafis Dunia 1. Jakarta: DGI Press.

[6] Kiloo. (2015). Subway Surfers, World Tour Paris (Version 1.42.0). https://play.google.com/store/apps/details?id=com.kiloo.subwaysur $\mathrm{f} \& \mathrm{hl}=\mathrm{en}$

[7] Rogers, S. 2014. Level up! The guide to great video game design (Second Edition). New Jersey: Wiley.

[8] Rouse III, R. 2004. Game Design: Theory and Practice (Second Edition). Burlington: Jones \& Bartlett Learning.

[9] Sago Sago. (2014). Sago Mini Babies Dress Up (Version 1.1). https://itunes. apple.com/app/sago-mini-babies-dress-up/id11322 13599

[10] Schell, J. 2014. The Art of Game Design: A Book of Lenses (Second Edition). Massachusetts: A K Peter 